\title{
Urodimento
}

REVISTA DE ESTUDOS EM ARTES CÊNICAS

E-ISSN 2358.6958

\section{Amantes em confinamento: A videochamada como dispositivo cênico}

Olívia Camboim Romano

Marcelo Alves Brazil

Para citar este artigo:

ROMANO, Olívia Camboim; BRAZIL, Marcelo Alves. Amantes em confinamento: A videochamada como dispositivo cênico. Urdimento - Revista de Estudos em Artes Cênicas, Florianópolis, v. 2, n. 41, set. 2021.

doi DOI: http:/dx.doi.org/10.5965/1414573102412021e0122

Este artigo passou pelo Plagiarism Detection Software | iThenticate 


\author{
Olívia Camboim Romano1 \\ Marcelo Alves Brazil²
}

\title{
Resumo
}

Neste artigo, os autores apresentam uma reflexão sobre o processo de criação do vídeo teatral Amantes em confinamento, relativa, especialmente, ao texto, à atuação e à sonoplastia. O trabalho foi realizado de forma remota, entre setembro de 2020 e janeiro de 2021, no âmbito da extensão universitária da Universidade Federal de Sergipe. A construção foi colaborativa e contou com docentes e discentes dos cursos de Teatro e de Cinema e Audiovisual. A videochamada foi tomada como dispositivo cênico e não somente como ferramenta de comunicação, ensaios e captação de imagens. O trabalho nos mostrou que é possível criar colaborativamente, ensaiar e atuar por meios remotos, e nos motivou a seguir investigando esse formato.

Palavras-chave: Extensão Universitária. Processo colaborativo. Sonoplastia. Trabalho remoto. Videochamada.

\section{Amantes em confinamento: The video call as a scenic device}

\begin{abstract}
In this article, the authors present a reflection on the creation process of the theatrical video Amantes em confinamento, particularly regarding the text, acting and sound design. The work was carried out remotely, between September 2020 and January 2021, within the scope of the university extension of the Universidade Federal de Sergipe. The construction was collaborative and included teachers and students from the Theater and Film and Audiovisual courses. The video call was taken as a scenic device and not only as a tool for communication, rehearsals and image capture. The work showed us that it is possible to collaboratively create, rehearse and act by remote means, and it motivated us to continue investigating this format.
\end{abstract}

Keywords: University Extension. Collaborative process. Sound design. Remote work. Video call.

Doutora em Artes Cênicas pela Universidade Federal da Bahia (UFBA), Mestre em Teatro e Licenciada em Artes Cênicas pela Universidade do Estado de Santa Catarina (UDESC). Licenciada em Educação Artística Habilitação Artes Cênicas (UDESC). Professora da Universidade Federal de Sergipe (UFS). camboim.olivia@gmail.com

http://lattes.cnpq.br/2092658668329862

iD https://orcid.org/0000-0003-0877-1873

2 Doutor em Música pela Universidade Federal da Bahia (UFBA). Mestre em Música pela Universidade Estadual Paulista "Júlio de Mesquita Filho" (UNESP). Licenciado em Música pela Universidade Federal de Pernambuco (UFPE). Professor da Universidade Federal de Sergipe (UFS). brazilmar@academico.ufs.br

http://lattes.cnpa.br/0600804542530056

(1) https://orcid.org/0000-0002-1221-3228 


\section{Amantes em confinamento: La video llamada como dispositivo escénico}

\section{Resumen}

En este artículo, los autores presentan una reflexión sobre el proceso de creación del video teatral Amantes em confinamento, particularmente en lo que respecta al texto, la interpretación y el diseño sonoro. El trabajo se realizó de forma remota, entre septiembre de 2020 y enero de 2021, en el ámbito de la extensión universitaria de la Universidade Federal de Sergipe. La construcción fue colaborativa e incluyó a profesores y alumnos de los cursos de Teatro y Cine y Audiovisual. La video llamada se tomó como un dispositivo escénico y no solo como una herramienta de comunicación, ensayos y captura de imágenes. El trabajo nos mostró que es posible crear, ensayar y actuar de forma colaborativa por medios remotos, y nos motivó a seguir investigando este formato.

Palabras claves: Extensión Universitaria. Proceso colaborativo. Diseño sonoro. Trabajo remoto. Video llamada. 


\section{A peste 0 teatro}

O teatro, de algum modo, flerta com a peste desde suas origens. A célebre tragédia grega Édipo Rei, de Sófocles (496 a.C. - 406 a.C.), por exemplo, inicia com Tebas assolada pela peste.

O CORO - Ah! Sofro males sem conta. Todo o meu povo está exposto ao flagelo, e meu pensamento não possui arma que nos permite uma defesa. Os frutos desta nobre terra não crescem mais à luz, e felizes nascimentos não coroam mais o trabalho que arranca gritos às mulheres. Um após outro, podem-se ver os tebanos, quais aves ligeiras, mais céleres que a chama indomável, precipitarem-se na região onde reina o deus do Poente. E a Cidade perece nessas mortes sem conta. Nenhuma piedade a seus filhos que jazem no chão: eles também são portadores da morte, ninguém geme sobre eles. Esposas, mães de cabelos brancos, todas se dirigem ao pé dos altares, suplicantes, chorando seus atrozes sofrimentos. O canto irrompe, acompanhado de um coro de soluços. Salva-nos, filha deslumbrante de Zeus, envia-nos teu auxílio radioso! (Sófocles, 2002, p.16-17).

Em meados do século XVI, no período elisabetano, o teatro londrino lidou com inúmeras interdições devido à peste bubônica que matou milhões de pessoas; pois, "As autoridades da cidade viam o teatro como um antro de doenças, letal nas epidemias e insalubre em outras épocas [...]” (Honan, 2001, p.192).

Em 06 de abril de 1933, Antonin Artaud (1896-1948) realizou na Sorbonne, em Paris, a conferência O Teatro e a Peste, em que a partir de apontamentos clínicos sobre a Grande Peste de Marselha (1720-1722) e sobre a peste bubônica na Itália (em meados do século XIV), entre outras epidemias, fez uma analogia entre a peste e o teatro. O ator francês, que representou um ponto de partida para a renovação do teatro ocidental na segunda metade do século XX ao defender a criação de uma linguagem cênica dirigida aos sentidos e ao combater o teatro psicológico e à servilidade à palavra, além de conferir ao encenador o papel de criador, afirmou, dentre outras questões, o seguinte:

Entre o pestilento que corre gritando em busca de suas imagens e o ator que persegue sua sensibilidade; entre o vivo que se compõe de personagens nas quais sem isso nunca teria pensado, e que as realiza no meio de um público de cadáveres e de alienados delirantes, e o poeta 
que inventa intempestivamente certas personagens e as entrega a um público igualmente inerte ou delirante, há outras analogias que explicam as únicas verdades que importam e que põem a ação do teatro e a peste no plano de uma verdadeira epidemia (Artaud, 1987, p.36).

No início do século XX, o teatro foi impactado pela gripe espanhola. Além disso, ao longo de sua existência enfrentou outras "pestes" como as guerras que muitas vezes suspenderam as atividades teatrais, as ditaduras e suas proibições e/ou censuras aos espetáculos e perseguições aos artistas.

E agora, em pleno século XXI, o teatro padece com a pandemia da Covid-19. Os primeiros casos de infecção com o vírus Sars-CoV-2 foram registrados em dezembro de 2019, na cidade de Wuhan, na China. No Brasil, o primeiro caso confirmado oficialmente foi em 26 de fevereiro de 2020 e, desde então, sobretudo desde março de 2020, com os decretos estaduais e municipais para enfrentamento e prevenção à propagação da Covid-19, o setor teatral está em crise. Esta crise econômica se deve tanto à interrupção por tempo indeterminado das atividades teatrais, ao fechamento dos espaços culturais, como à perda de muitos(as) artistas, dentre eles: Antônio Bivar (1939-2020), Eduardo Galvão (19622020), Fernando Neves (195?-2020), Gésio Amadeu (1947-2020), Ismael Ivo (19552021), Luis Carlos Rossi (1954-2021), Nicette Bruno (1933-2020), Paulo Gustavo (1978-2021), entre tantos(as) outros(as). Aliás, enquanto este artigo está sendo redigido, entre o final de março e o início de junho de 2021, com registros de 800 a 2.000 mortes por dia decorrentes da Covid-19 e mais de 488.000 óbitos desde o início da pandemia, o Brasil alcança recordes diários alarmantes.

Em diversos lugares do mundo, desde o início da pandemia, as atividades foram catalogadas como essenciais ou não essenciais e o teatro foi classificado como não essencial. Os teatros ficaram no fim da fila da reabertura; pois, além de considerados não essenciais, pela proximidade de artistas, técnicos e espectadores, são tidos como muito perigosos; contraditoriamente, mais perigosos do que academias de ginástica, centros comerciais, salões de beleza e locais de cultos religiosos.

O processo de reabertura iniciou em tempos diferentes em cada lugar (país e/ou estado) e seguindo vários protocolos de biossegurança. No Brasil, por 
exemplo, desde o final de 2020, concomitante aos experimentos virtuais, já há notícias de espetáculos teatrais com distanciamento social ao ar livre ou em janelas (ou varandas) residenciais ou em telhados, com os espectadores assistindo às obras de suas próprias residências ou sentados, separados, em cabines individuais ou acomodados em seus carros para assistir às sessões de teatro drivein.

Para driblar o confinamento, muitos artistas e companhias teatrais (locais, nacionais e internacionais), disponibilizaram leituras dramáticas e vídeos de suas peças de teatro, gravadas antes da pandemia e/ou produzidas durante a pandemia em casa e/ou em teatros vazios. Nesse período, pudemos acompanhar,

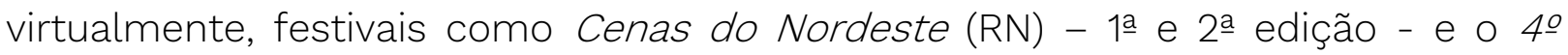
Festinfante (SC); séries como Horas em Casa com Denise Fraga; o espetáculo de teatro escuro/auditivo virtual Todo que oír, de Marcela Juárez e Guillermo Dillon, de Tandil (Argentina); entre inúmeras outras produções gravadas e transmitidas ao vivo.

Pedro Bennaton, do ERRO Grupo (SC), alerta que:

Essa bem-intencionada atual proliferação da divulgação de peças gravadas, leituras dramáticas e até peças sendo feitas ao vivo nas redes (anti)sociais como solução para esse período que enfrentamos pode ter um efeito exatamente oposto ao seu objetivo principal, que é o de salvar o teatro. Também pode não acarretar em problemas futuros, pois é sinal de que existe uma ansiedade em não pararmos de fazer teatro. No entanto, pode ser tudo o que as grandes corporações do mercado cibernético almejam, que é dominar esta que pode ser a última fronteira da presença e da precariedade dos encontros sociais. Duas qualidades que o teatro resiste em perder ao longo de séculos (2020).

Por outro lado, conforme percebido por nós e outros(as) pesquisadores(as), professores(as) e artistas que vivem distantes dos grandes centros, essa disponibilização de conteúdos e a facilidade de acesso a eles tem seu lado positivo. Vivendo em Sergipe, no caso, sabemos que é quase impossível assistir às produções teatrais de outros estados e estrangeiras, sobretudo, porque a maioria delas não chega até aqui. Também é muito difícil acompanhar todos os espetáculos locais que se apresentam na capital, pois, por exemplo, as disciplinas da licenciatura em Teatro da Universidade Federal de Sergipe (UFS) são ofertadas 
no período noturno, ou seja, no horário em que comumente os espetáculos estão em cartaz e/ou acontecem suas apresentações únicas.

Segundo a professora Marcela Arpes, de Santa Cruz - Argentina,

Este acceso libre a los contenidos teatrales y artísticos en general es, para quien se dedica al teatro como pulsión vital, no solo entretenimiento (en el peor de los casos) o vivencia de la experiencia del acontecimiento artístico (en el mejor de ellos) sino también, una modalidad de aprendizaje e incitaciones o motivaciones para los propios proyectos creativos (2020, p.112).

Seguindo a lógica de Jorge Dubatti, o teatro é um acontecimento convivial e as outras modalidades de convívio mediadas pela tecnologia podem ser chamadas de tecnoviviais. Segundo o crítico e teórico teatral argentino,

Se pueden distinguir dos grandes formas de tecnovivio: el tecnovivio interativo (el teléfono, el chateo, los mensajes de texto, los juegos en red, el skype, etc.), en el que se produce conexión entre dos o más personas; y el tecnovivio monoactivo, en el que no se establece un diálogo de ida y vuelta entre dos personas, sino la relación de una con una máquina o con el objeto o dispositivo producido por esa máquina, cuyo generador humano se ha ausentado, en el espacio y/o en el tiempo (Dubatti, 2014, p.125).

É evidente que ir ao teatro, que assistir a um espetáculo teatral ao vivo, presencialmente, compartilhar essa experiência com os artistas e com os outros espectadores, de maneira nenhuma será substituída por assistir a uma gravação ou a uma transmissão ao vivo por uma tela; nem mesmo em um acontecimento teatral híbrido, ou seja, uma obra teatral que usa mídias digitais.

El teatro neotecnológico, en su propuesta liminal (cruce, puente, zona compartida entre experiencia convivial y tecnovivial), no pretende reemplazar ni superar el teatro de presencia física, pero en tiempos de necesidad encauza la expresión de los artistas y garantiza la salida laboral (Dubatti, 2020, p.25).

Acreditamos que, para além de contribuir com a subsistência dos artistas, com a manutenção dos grupos e a sustentação dos laços entre os artistas e os espectadores, essas experiências teatrais on-line, em alguma medida, também aproximam pessoas que não tinham o hábito de frequentar o teatro e consistem 
em “[...] un acontecimiento de expectación potente” (Arpes, 2020, p.113).

\section{Uma pequena síntese do enredo}

Durante esse período de distanciamento social, ainda em curso, que já passou por várias fases, de acordo com cada localidade, como quarentena e lockdown, nós, como muitos(as) outros(as) professores(as) e artistas de teatro, impossibilitados(as) da comunhão com nosso público e do encontro presencial, buscamos novas formas de trabalho por meio remoto, inclusive para nutrir nossos vínculos pedagógicos e artísticos com os(as) estudantes e espectadores(as). Assim, desde setembro de 2020 estamos desenvolvendo projetos de extensão universitária de forma remota, vinculados ao Departamento de Teatro (DTE) da UFS, com docentes e discentes das licenciaturas em Teatro, Música e Cinema e Audiovisual. Um desses projetos, Amantes em confinamento - uma cena tecnovivial em tempos de pandemia, desenvolvido entre 17 de setembro de 2020 e 17 de janeiro de 2021, gerou o vídeo teatral Amantes em confinamento publicado no YouTube em 17 de janeiro de $2021^{3}$. Cabe dizer que a gravação em vídeo atendeu uma das exigências do edital institucional de cadastro de projetos para desenvolvimento remoto ${ }^{4}$.

Amantes em confinamento, com cerca de 28 minutos de duração, elaborado a partir de elementos autobiográficos, conta a história de um casal de amantes que tem um romance virtual. As personagens, violeta (uma mulher de aproximadamente 40 anos de idade) e Raul (um rapaz de cerca de 20 anos), em uma videochamada durante a pandemia da Covid-19, planejam um encontro presencial, conversam sobre suas histórias de vida, seus receios e seus sonhos. A obra fala sobre a paquera nas redes sociais, o amor em tempos de pandemia, os relacionamentos construídos pela janela do computador e, com certeza, representa muitos casos de amor contemporâneos.

Ao que tudo indica, Violeta (interpretada pela atriz Olívia Camboim,

${ }^{3}$ Disponível no seguinte link: https://youtu.be/J X-1gE7s5u.

${ }^{4}$ Edital no 08 PROEX-PIAEX/UFS de 29 de julho de 2020. 
coordenadora geral do projeto), está com seu marido em alguma cidade do continente europeu, no apartamento de parentes dele. Embora seu casamento esteja por terminar, segundo a personagem, cumpriram a viagem planejada anteriormente, mas não têm estimativa para retornar, pois estão com dificuldades para conseguir um voo e voltar ao Brasil. Raul (representado pelo estudante Josimario Cesar), aparentemente, está sozinho em casa, em alguma cidade do interior de Sergipe, enquanto sua mulher trabalha em um plantão. A trama, dentre outras questões, explora o desassossego por eles partilharem seus cotidianos junto aos seus companheiros e o receio do romance deles não progredir. O quadro piora quando Violeta conta que seu esposo pediu mais uma chance para o casamento deles. A cena, em tom bastante realista, gravada em uma sequência sem cortes e com pouquíssima edição, coloca o espectador como um voyeur que observa uma videochamada privada dos amantes durante a madrugada.

Amantes em confinamento, em diálogo com a realidade de parte das milhões de pessoas em todo o mundo que estão em confinamento, além de ter a pretensão de levar uma espécie de antídoto para a solidão de tantos(as) espectadores(as) confinados(as) e, de alguma maneira, contribuir para incentivar o distanciamento social e evitar o contágio da Covid-19, explorou alternativas metodológicas de criação em modo remoto.

\section{O processo colaborativo}

A construção do vídeo teatral foi colaborativa, um processo em que todos(as) os(as) membros(as) da equipe, apesar da distribuição de funções, foram considerados(as) criadores(as), tiveram a oportunidade de contribuir com base em suas memórias e experiências de vida e puderam intervir e opinar sobre os diferentes elementos do vídeo (atuação, cenário, composição musical, edição figurino, texto etc.).

Segundo a pesquisadora Stela Fischer,

Conceitualmente, entende-se por processo colaborativo o procedimento de grupo que integra a ação direta entre ator, diretor, dramaturgo e 
demais artistas, sob uma perspectiva democrática ao considerar o coletivo como principal agente de criação e aglutinação de seus integrantes. Essa dinâmica propõe um esmaecimento das formas hierárquicas de organização teatral, embora com imprescindível delimitação de áreas de trabalho e delegação de profissionais que as representam (2010, p.61-62).

Seguindo essa característica do processo colaborativo, em Amantes em confinamento, apesar da horizontalização das relações entre os integrantes da equipe de criação, as funções e as distribuições de tarefas entre os quatro estudantes bolsistas foram feitas da seguinte maneira: Josimario Cesar com o plano de trabalho Ator em vídeo teatral, Rubens Severino com Dramaturgista de vídeo teatral, Junior Santos com Edição de vídeo teatral e Marvi Oliveira com o plano de trabalho Sonoplastia de vídeo teatral.

Além dos quatro estudantes bolsistas remunerados, o trabalho contou com alguns(as) colaboradores(as) externos: Maria Flor Brazil, produtora, diretora e fotógrafa, da Banda Filmes (RJ) que nos assessorou; o escritor e professor da Universidade Federal do Recôncavo da Bahia (UFRB) Rubens da Cunha que consentiu com a citação de sua crônica Despedida e o músico e compositor Zé Manoel que permitiu a inserção de sua composição Canção e Silêncio no vídeo.

Definir os atores e atrizes que participarão de um trabalho artístico é uma etapa difícil e determinante no processo de construção. Em geral, em um filme, “Essa responsabilidade é, inevitavelmente, dividida entre o produtor executivo (que vai negociar e estabelecer um contrato com o ator) e o diretor (que vai comandálo no filme) [...]" (Gerbase, 2007, p.22).

No caso do projeto de extensão universitária em questão, a definição dos estudantes integrantes da equipe de criação, inclusive para a função de ator, passou, primeiramente, pelos candidatos inscritos no Sistema Integrado de Gestão de Atividades Acadêmicas (SIGAA) da UFS. Em segundo lugar, pelas condições estruturais (dispositivo eletrônico e internet) e flexibilidade para participar de reuniões online, ensaiar e gravar, inclusive nos finais de semana e no período noturno, ou seja, nos horários mais silenciosos. Em terceiro lugar, pela disponibilidade para atuar voluntariamente; pois Amantes em confinamento foi 
contemplado nos dois primeiros meses com apenas duas bolsas remuneradas e, somente, nos dois últimos meses com quatro bolsas remuneradas. Em quarto lugar, pelo currículo dos candidatos, sendo que, a maioria dos interessados possuía pouca ou nenhuma experiência nas atividades previstas em seus planos de trabalho e, a maioria, era do quarto período acadêmico de seu curso.

No caso do plano de trabalho de atuação, não foi levada em conta a idade e o tipo físico dos candidatos. Após uma pré-seleção, foi solicitado que os interessados gravassem com seu próprio celular uma cena individual curta para os vermos atuando. Inicialmente, idealizamos contar a história de um casal apaixonado que planejava uma fuga do confinamento e que, no fim, conseguiria se encontrar pessoalmente. Mas, com a manutenção do distanciamento social e a entrada do estudante Josimario Cesar para contracenar com a professora e coordenadora do projeto, muito mais velha do que ele, a ideia foi repensada e alterada.

Em relação ao plano de trabalho Dramaturgista de vídeo teatral, cabe dizer que entendemos que esta função auxilia em todas as etapas criativas e assessora todos os artistas envolvidos no trabalho. O dramaturgista também é aquele que se coloca no lugar do público da obra. "[...] ao se identificar com o espectador, possibilita a leitura e a interpretação da reação do público. [...]" (Gonçalves Junior, 2019, p. 63). No entanto, algumas funções acabaram se convertendo e/ou se desdobrando e/ou assumindo outras características ao longo do processo, sobretudo, a função de dramaturgista, assumida por Rubens Severino, que, de certa forma, se transmudou em preparação de atores(atrizes).

Essas mudanças de função que ocorrem em um processo colaborativo, são destacadas por Tânia Boy:

Em muitas produções do teatro de grupo existe uma ênfase nas criações que articulam processos coletivistas e isso reafirma a própria noção de grupalidade buscando um outro diálogo com o conjunto da criação teatral e desfaz as fronteiras que a rigidez das funções criativas estabeleceu no teatro (2008, p. 221).

O processo de criação de Amantes em confinamento foi dividido em cinco 
etapas. Na primeira, fizemos pesquisas diversas sobre a Covid-19, relacionamentos virtuais, entre outras; improvisações para o levantamento das cenas; assim como, criamos um banco de imagens e sons que nos serviram como referências de arte. $\mathrm{Na}$ segunda etapa, estruturamos o texto da cena a partir do levantamento efetuado anteriormente. Na terceira etapa, lapidamos o texto, estabelecemos as marcações de cena e pensamos em seus aspectos visuais e sonoros. Sendo que, muitos ensaios foram gravados e isso propiciou que os atores pudessem ver sua atuação e extrair suas próprias contribuições. Na quarta etapa, gravamos e editamos o material, incluindo a sonoplastia. Na quinta etapa, em meados de janeiro de 2021, divulgamos e publicamos o vídeo no YouTube, que está com cerca de 750 visualizações e dezenas de marcações como "gostei".

Cabe um destaque ao processo de gravação que exigiu uma série de ajustes para que a cena se tornasse crível. Para isso, os atores criaram perfis na rede social Facebook com os nomes das personagens e foi necessário alterar os nomes que aparecem no canto inferior esquerdo de cada janela da chamada de vídeo através do Google Meet. Outro detalhe é que este aplicativo permite a gravação das videochamadas, mas registra no arquivo final apenas a imagem da pessoa que está falando em cada momento, algo não desejável no nosso vídeo como um todo. Para que, no layout da tela, as duas personagens estivessem visíveis na cena na maior parte do tempo e fosse possível registrar não só as falas individuais, mas também as reações de cada uma durante as falas, foi necessário realizar um registro através de um software de captura de tela, o Camtasia Studio 8.0 (Figura 1). 


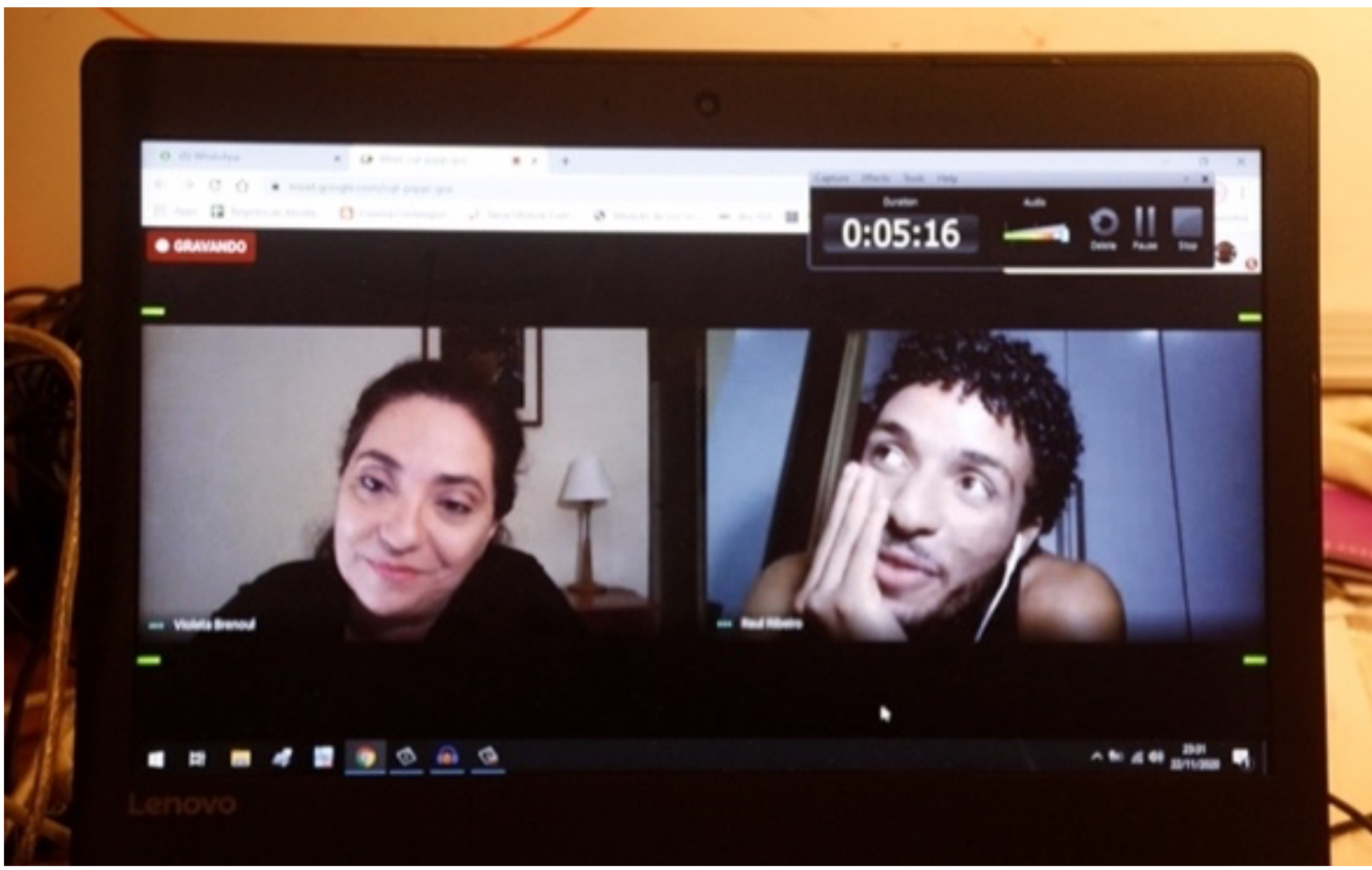

Acervo: Olívia Camboim e Marcelo Brazil

A gravação da trilha sonora original, também realizada no ambiente doméstico, passou pelos mesmos problemas de captação de ruídos indesejados do vídeo e teve que ser feita nos horários mais silenciosos. Com exceção do tema de abertura, concebido com sons eletrônicos, foi registrada com um violão e um único microfone através do software de gravação e edição Reaper (Figura 2). Todo o processo de edição e mixagem da trilha foi executado previamente e incluído na edição final do vídeo, realizada no software VEGAS Pro 17. 
Figura 2 - Marcelo Brazil durante o processo de gravação da trilha sonora original

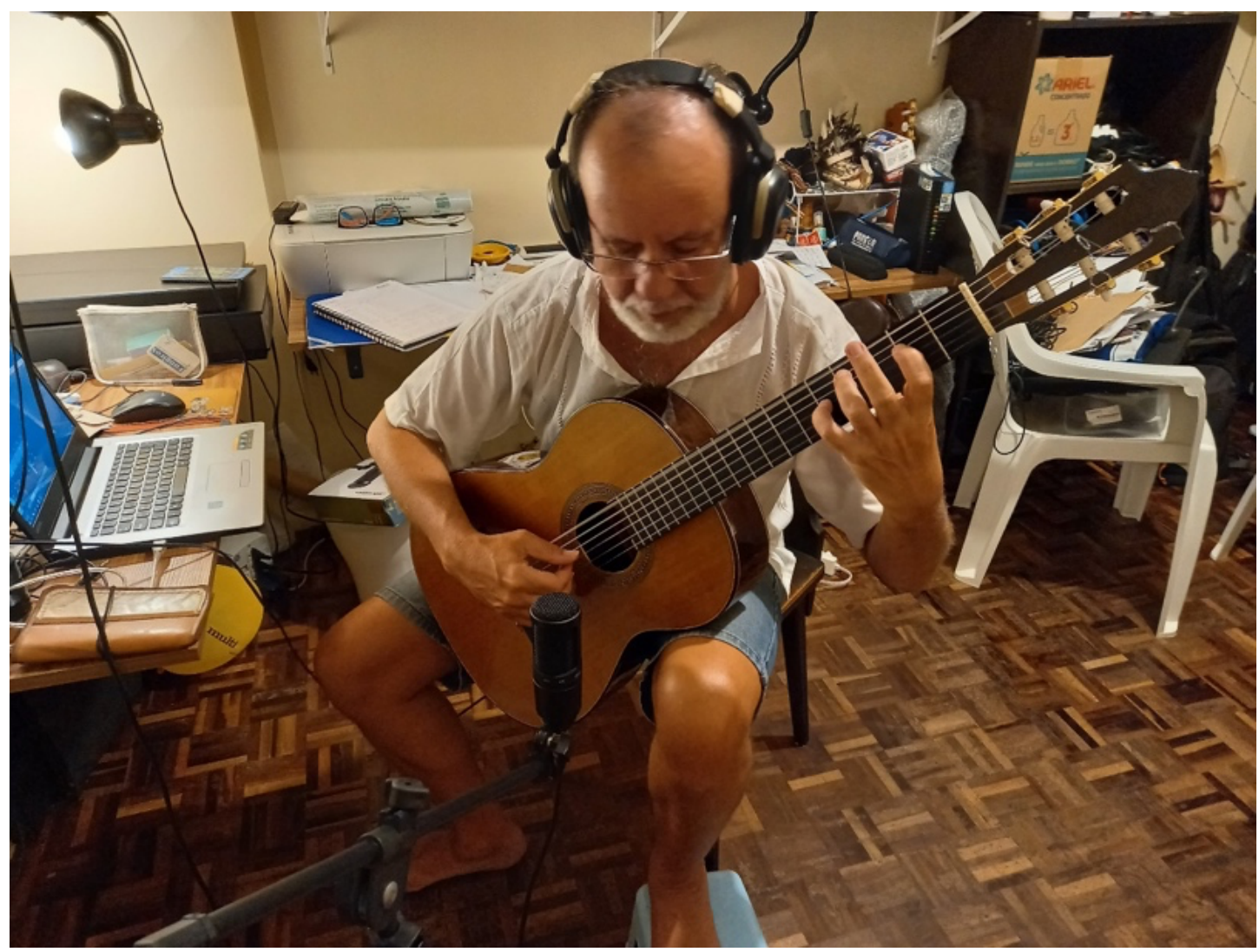

Acervo: Olívia Camboim e Marcelo Brazil

\section{Atuação e os desafios do ensaio aberto}

Pautados nas proposições de Stanislavski $(1989,1984,1986)$ para o trabalho do ator, as ações das personagens foram divididas em ações interiores e exteriores. Os atores buscaram, em cena, agir durante todo o tempo, ininterruptamente; pois, partimos do pressuposto que mesmo quando nosso corpo não está em movimento (imobilidade exterior), nossa mente está em plena atividade (mobilidade interior), isto é, uma imobilidade criativa. Assim, as ações foram pensadas a partir de objetivos predefinidos relativos às personagens e atrelados com a imaginação dos atores. Stanislavski (1986) aponta que a utilização do "se" serve como um trampolim para o ator sair do plano real e entrar no terreno da imaginação. O ator, consciente que não é a personagem, atua como "se" fosse a personagem, como agiria "se" passasse por tal situação. Através do "se" o ator 
acende sua imaginação, identifica-se com a personagem, gerando em si mesmo reações internas e externas. Ele acredita cenicamente na possibilidade; ou melhor, naquilo que não é, mas poderia ser.

No início do processo de Amantes em confinamento, após a criação do texto dramatúrgico (roteiro), dedicamos vários encontros remotos para os ensaios de mesa, em que destrinchamos e detalhamos as relações vigentes no texto e nos possíveis universos interiores das personagens. Nesta fase do trabalho, todos nós, integrantes da equipe, especialmente os atores, expusemos nossos pontos de vista com relação aos problemas e às ideias apresentadas, analisamos cada elemento e imaginamos sua representação. Em seguida, dividimos o texto em partes para estabelecer os objetivos das personagens e, consequentemente, o percurso de suas ações. "O objetivo será o farol que aponta o caminho certo [da personagem]" (Stanislavski, 1986, p.142), encadeado de forma lógica e coerente.

Em consonância com uma atuação naturalista, ou seja, uma representação mimética fidedigna da realidade que é crível e dá a impressão de ser natural e não uma cena ensaiada, buscamos, nos encontros semanais remotos, veracidade na interpretação e rompimento com o artificialismo, sobretudo com o desempenho declamatório, algo que temos observado com frequência em trabalhos teatrais locais.

Os ensaios remotos, desde nossas casas e privados do contato dos corpos, foram bastante desafiantes, demandaram composições com atraso (delay), com algumas quedas de sinal de internet, com as falhas de áudio, com ruídos alheios ao trabalho. A composição foi feita tendo em conta a câmera dos notebooks/tablets; sendo que, quando os atores olhavam para a câmera, em tese, estabeleciam uma conexão com o olhar dos espectadores e quando olhavam para a tela, interagiam entre eles ou olhavam para si próprios, como se estivessem diante de um espelho.

Em novembro de 2021, realizamos um ensaio aberto ao vivo, via Google Meet, e esse encontro com os espectadores foi imprescindível para a construção do trabalho. Segundo Stela Fischer, o caráter processual do trabalho colaborativo: 
[...] delega à obra uma moldagem que vai se desenhando conforme a sua elaboração em conjunto, a partir do cruzamento das diferentes áreas, desde o momento inicial até o encerramento das apresentações, considerando também o público como colaborador desse complexo coletivo e aberto (2010, p.62).

No ensaio ao vivo, gravado e seguido de um bate-papo, pedimos que os espectadores mantivessem suas câmeras abertas para podermos ver suas reações e, de alguma maneira, vivenciarmos a emoção do encontro. O link foi enviado por e-mail apenas para quem o solicitou. Mas, como um evento público virtual em que os internautas podem se esconder por trás de câmeras fechadas, de nomes falsos e de fotos de perfil roubadas, fomos surpreendidos com uma invasão em que o ensaio foi "bombardeado" com imagens impróprias, desrespeitosas e indesejadas. Primeiramente, compartilharam um vídeo pornográfico e, devido nossa perplexidade e, na época, pouca familiaridade com as funções do Google Meet, como impedir compartilhamentos de tela, pausamos o ensaio por cerca de um minuto e ficamos as voltas com aquelas imagens de sexo explícito, heterossexual, branco e, provavelmente, estadunidense. Na segunda invasão, um rapaz abriu o microfone e começou a intervir na ação dramática com diferentes comentários a partir de nossas falas, além de fazer várias postagens desrespeitosas no chat. Na terceira, com o compartilhamento de uma imagem animada (um GIF), interrompemos uma vez mais o ensaio, excluímos da videochamada várias pessoas que eram de fora do domínio da UFS, especialmente as que estavam com a câmera fechada e, apesar da tentativa delas em acabar com o ensaio, pudemos concluir a sessão de trabalho.

Os ataques virtuais em reuniões, eventos, videoconferências e aulas online em diferentes plataformas (Skype, Google Meet, WhatsApp, Zoom, entre outras), lamentavelmente, se tornaram um fenômeno comum durante o período de isolamento social em que um grupo de pessoas, com nomes comuns, acessa o link de uma videochamada e conturba de diferentes maneiras o evento por escárnio, motivações políticas, racismo, violência de gênero e/ou tentativa de silenciamento. 


\section{A videochamada como dispositivo cênico}

Seguindo a dinâmica da videochamada e com o tempo real coincidindo com o ficcional, o espectador de Amantes em confinamento, como um voyeur e diante de atuações naturalistas, acompanha praticamente sem cortes a conversa privada do casal. Nesse caso, a videochamada pelo Google Meet foi tomada como dispositivo cênico e não somente como ferramenta de comunicação, ensaios e captação de imagens. Em certa medida, ela foi nosso pré-texto para a investigação e para isso nos pautamos no pensamento da estudiosa Beatriz Ângela Vieira Cabral:

O pré-texto é o roteiro, história ou texto que fornecerá o ponto de partida para iniciar o processo dramático, e que irá funcionar como pano de fundo para orientar a seleção e identificação das atividades e situações exploradas cenicamente (2006, p.15).

O vídeo inicia com imagens da praia Aruana, em Aracaju-SE, captadas pelos coordenadores do projeto no segundo semestre de 2020 e a narração de um trecho da crônica Despedida de Rubens da Cunha; seguida de uma troca rápida de mensagens de texto entre as personagens no Facebook Messengerem que elas combinam uma videochamada.

Figura 3 - Cena de Amantes em confinamento (2021)

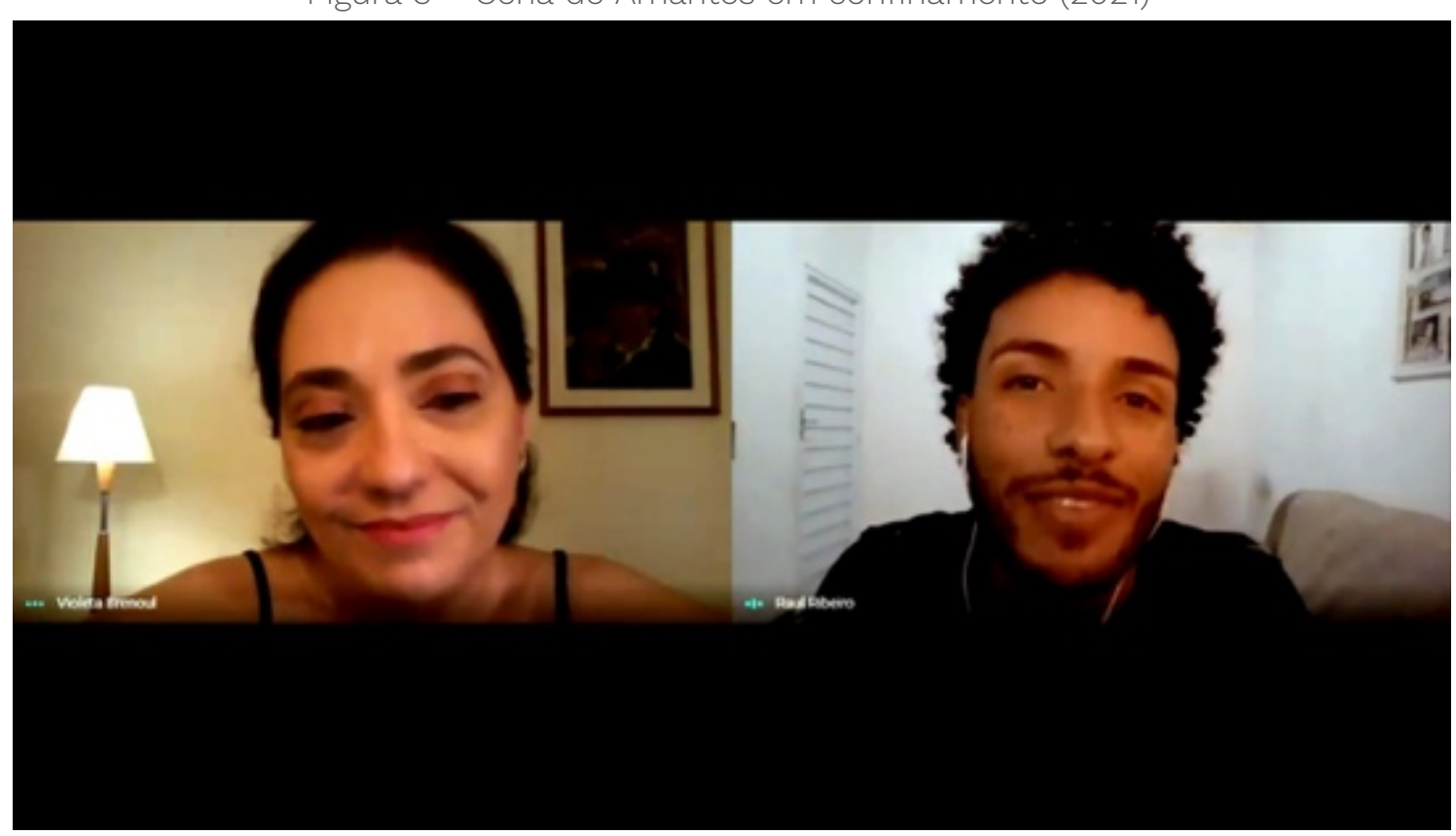

Acervo: Olívia Camboim e Marcelo Brazil 
Apesar do predomínio do primeiro plano (ou plano próximo), com alguns planos detalhes e médios, em Amantes em confinamento, é possível visualizar alguns elementos cenográficos que particularizam o espaço cênico das personagens (Figura 3). Na janela de Violeta, vemos, em uma parede bege ao fundo, o quadro Pássaro Vermelho - óleo sobre madeira, $55 \times 35$ cm, s/d -, de Lenio Braga, acima de um aparador de madeira com um abajur de mesa. Na janela de Raul, percebemos que ele está em uma peça estreita, com paredes brancas um pouco manchadas; compõe a cena um sofá bege, uma porta branca ventilada de alumínio - estilo palheta - e numa das paredes laterais há um banner impresso em lona com fotos coloridas de crianças. Esses cenários foram pensados ao longo do processo de criação com elementos encontrados nas residências dos atores. É possível perceber ainda uma diferença de iluminação entre as janelas das personagens: a de Violeta mais elaborada (quente) e a de Raul, basicamente, a luz branca do ambiente (fria). Mesmo baseadas em recursos caseiros (abajur e luminárias de bancada com lâmpadas de LED comuns), em cada ambiente utilizou-se apenas o que estava disponível. Apesar do caráter de improvisação no que se refere à iluminação, o resultado contribuiu para criar um ambiente mais sofisticado para Violeta e destacou a simplicidade do cenário de Raul, fato também ressaltado pelo figurino, a bebida que consomem e as referências culturais que mencionam. Enquanto Violeta toma vinho tinto e cita Garcia Marquez e Nelson Rodrigues, Raul bebe cerveja e canta um pequeno trecho de música popular atual (Partilhar de Anavitória e Rubel). 


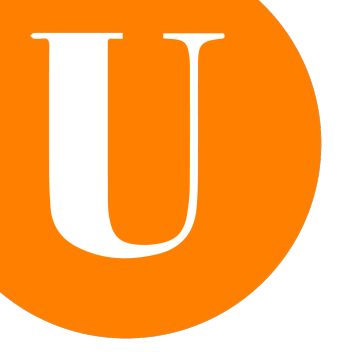

Amantes em confinamento: A videochamada como dispositivo cênico

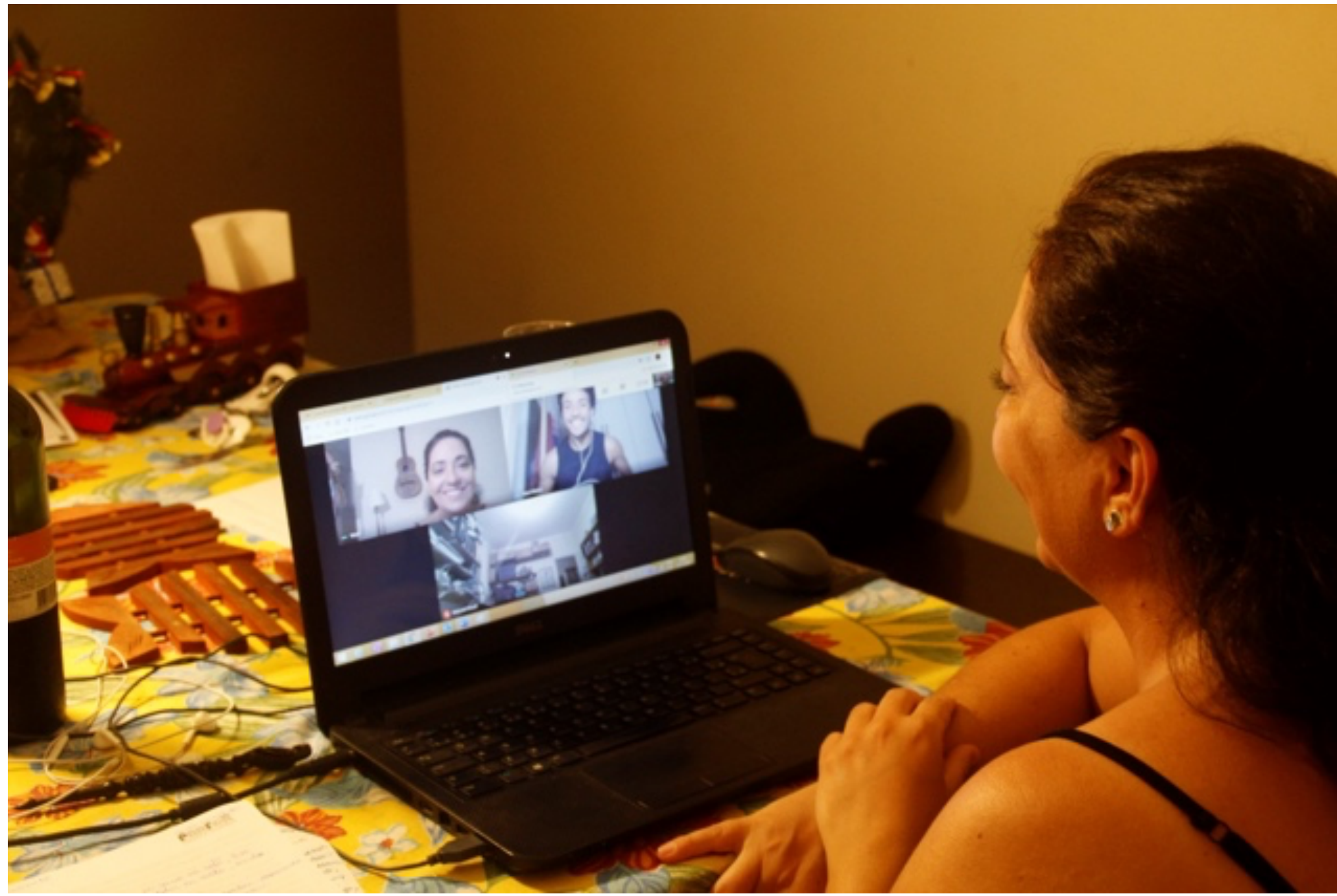

Acervo: Olívia Camboim e Marcelo Brazil

A opção de utilizarmos câmeras fixas durante as capturas, do próprio notebook da atriz (Figura 4) e do tablet do ator, no caso, não revelando o entorno dos ambientes, se aproxima de uma realidade bastante comum nesse tipo de conversa, onde os envolvidos se sentem, muitas vezes, pouco à vontade para permitir essa quebra de privacidade. No contexto da ficção, permite também nos fazer questionar se as personagens estão realmente onde afirmam que estão e até se estão escondendo algo de sua vida pessoal, se estão mesmo sozinhas ou não. 


\section{Criação da trilha sonora original e sonoplastia}

Completando a composição cenográfica de Amantes em confinamento, a música incidental, criada durante o processo colaborativo, buscou dialogar com o ambiente visual estabelecido para a cena e a proposição da dramaturgia. Destacamos a importância da participação do criador, Marcelo Brazil, em todo o processo.

De acordo com entrevista concedida pelo compositor Rafael Ferrari:

O ideal é o processo onde o compositor está acompanhando toda a evolução da criação dos personagens, da movimentação, do cenário, do figurino, onde ele é realmente uma parte integrante daquele trabalho, não é uma coisa a parte que ele faz na casa dele, só pensando com as ideias dele, tem uma série de coisas ali envolvidas, de várias pessoas, de vários profissionais (apud Chaves, 2011, p.50).

Toda a música da cena foi elaborada a partir do tema de cinco notas (Ré, Lá, Dó, Mi, Fá) que compõe a abertura em um ritmo de cinco pulsos (sons graves), bastante incomum nas criações de música popular e que, por esta razão, costuma soar estranho aos ouvintes habituados aos ritmos em dois, três ou quatro pulsos. Esse pequeno tema, que remete a COVID (cinco letras), funcionou como elemento gerador de melodias e harmonias de toda a música incidental, com exceção da composição final, de autoria de Zé Manoel. Ainda assim, existem relações musicais intrínsecas entre a trilha original e a canção final. As criações musicais para a cena fazem uso de um sistema conhecido como modalismo e criam uma sensação de flutuação, onde não se percebem fortes intenções de suspensão e repouso, característica do sistema tonal, predominante na música popular e utilizado na canção de Zé Manoel. Podem ser utilizados os mesmos conjuntos de notas musicais nos dois sistemas (modal e tonal) e se obter resultados ou "climas" bastante distintos para a criação musical, e é exatamente neste ponto que as criações dialogam: apesar de baseadas, de uma forma geral, no mesmo conjunto de notas, criam climas distintos, fortalecidos ainda pelo uso de letra na canção final. Essa dualidade entre a instabilidade musical dos temas da cena e a estabilidade conclusiva da canção final contribui para reproduzir, em outra camada 
de percepção, a relação frágil entre as personagens e a possível sensação de impotência e indefinição vivenciada por muitas pessoas na pandemia em andamento. Apesar do sentido conclusivo da canção final, tanto em sua construção musical quanto em sua letra, muitas indagações podem ser geradas sobre o que realmente aconteceu com as personagens após o suposto fim do relacionamento ou até se estavam mesmo sendo verdadeiras durante a relação virtual.

Complementando a trilha do vídeo, alguns efeitos de ambientação sonora foram utilizados com o intuito de dar veracidade à cena, como, por exemplo, um discreto ruído de uma tampa de garrafa caindo na mesa no momento em que Raul se levanta para pegar uma bebida. No teatro, é comum utilizarmos o termo sonoplastia incluindo toda a parte sonora da montagem, ou seja, trilha musical e ruídos e a compreendemos tal como expõe Carmen Lúcia José:

A sonoplastia pode ser entendida como o conjunto de elementos sonoros disponíveis para a composição da paisagem sonora; esse conjunto de elementos equivale-se a qualquer outro conjunto de sinais que, originariamente, são dotados da capacidade de funcionar como suporte material, isto é, como material significante da comunicação sonora (2007, p.181-182).

Na cena de abertura, um recurso de sonoplastia foi necessário para minimizar a má qualidade do áudio da imagem do mar, captada com um celular comum e prejudicado pela interferência do vento no microfone do aparelho. Neste caso, o som do mar foi substituído por um arquivo disponível em um banco de áudios gratuitos da internet durante o processo de edição.

Diferente de uma apresentação em uma sala com público, onde eventuais ruídos da cena são facilmente incorporados ao que está sendo visto, em uma produção audiovisual, os ruídos indesejáveis ganham uma amplitude maior e podem se tornar ainda mais evidentes ao se utilizar um fone de ouvido. Quaisquer movimentos bruscos dos atores ou de carros que passem no momento da gravação são captados e registrados junto com as falas, sendo quase impossível minimizá-los no processo de edição. Esse problema se agravou pois não foram utilizados microfones adequados pelos atores e sim aqueles incorporados aos 
equipamentos por onde foi realizada a chamada de vídeo: um notebook e um tablet. Buscando minimizar os ruídos indesejados, as gravações foram realizadas durante a madrugada.

\section{Considerações finais}

Em agosto de 2020, quando submetemos a proposta do projeto de extensão para a elaboração do vídeo teatral Amantes em confinamento, todas as atividades acadêmicas presenciais estavam suspensas na UFS e as aulas remotas ainda não estavam sendo oferecidas no DTE. Particularmente, enquanto docentes de uma instituição pública de ensino superior, nos sentíamos muito apartados; pois nosso contato com a universidade se dava somente nas reuniões (mensais) do Colegiado e do Conselho de Curso de Teatro. Assim, a execução desse projeto, inclusive pela possibilidade de comunicação com alguns estudantes, nos animou, ocupou nossas cabeças de forma criativa e nos deu forças para permanecermos em casa, evitando assim o contágio e a propagação do vírus.

No decorrer do processo de criação, inclusive com a implementação das atividades de ensino remoto em meados de outubro de 2020, percebemos que as reuniões e os ensaios de Amantes em confinamento eram os raros momentos de convivência com os discentes; pois, lastimavelmente, enfrentamos a recusa e/ou a impossibilidade da maioria dos nossos alunos em ligar suas câmeras durante as aulas ou até mesmo de se comunicar por áudio, optando por comentários eventuais via chat. Desse modo, os encontros na ação de extensão tornaram-se praticamente o único momento de contato visual e de maior interação com estudantes da universidade, sobretudo com Josimario Cesar, Rubens Severino e Junior Santos que se envolveram e se dedicaram muito ao projeto. Assim sendo, esse trabalho se revelou fonte de diversas experiências relevantes, tanto artísticas quanto educativas.

Do ponto de vista artístico, nossa gravação ou o ensaio transmitido ao vivo não substituem a necessidade de vivência presencial do acontecimento teatral, pois, evidentemente, como já dito anteriormente, o teatro não se substitui por uma tela. No entanto, esse trabalho nos mostrou que, a partir da disponibilidade e 
entrega da equipe, é possível criar colaborativamente, ensaiar e atuar por meios remotos. Ademais, tomando como parâmetro as manifestações de algumas pessoas que assistiram ao vídeo postado no YouTube, além de termos atingido um nível satisfatório de qualidade, conseguimos estabelecer um diálogo com o tempo presente e tocar os espectadores.

Amantes em confinamento não é uma peça de teatro, mas também não é um vídeo ou um curta-metragem, é um trabalho híbrido realizado de forma remota com bases teatrais, um formato experimental que surgiu das necessidades impostas pela pandemia e alcançou seus objetivos. Além do mais, superou muito nossas expectativas de audiência, uma vez que, de acordo com nossa percepção, os trabalhos vinculados ao DTE-UFS exibidos no campus de São Cristóvão, realizam, em geral, apresentações únicas e têm um alcance pequeno de público, cerca de 5\% do número de visualizações que já tivemos até então. Resta-nos, diante disto, realizar novas experiências e aprofundar os conhecimentos sobre as possibilidades do formato.

\section{Referências}

ARPES, Marcela. El teatro pandémico en el extremo austral de la Argentina. Reseñas CeLeHis: Boletín del Centro de Letras Hispanoamericana, Mar del Plata, ano 7, n. 20, 2020. Disponivel em: https://fh.mdp.edu.ar/revistas/index.php/rescelehis/article/view/4667/4791. Acesso em: 08 mar. 2021.

ARTAUD, Antonin. O teatro e seu duplo. Tradução de Teixeira Coelho. São Paulo: Max Limonad, 1987.

BENNATON, Pedro. O teatro como respirador social: reflexões sobre arte presencial na pandemia. Revista Gulliver, 2020. Disponível em:

https://revistagulliver.com.br/teatro/o-teatro-como-respirador-social/. Acesso em: 10 mar. 2021.

BOY, Tânia Cristina dos Santos. Estética da existência na formação do professorartista. Urdimento, Florianópolis, n. 8, p. 215-229, 2008. Disponível em: https://www.revistas.udesc.br/index.php/urdimento/article/view/141457310211200 8215/8889. Acesso em: 04 jun. 2021. 
CABRAL, Beatriz Ângela Vieira. Drama como método de ensino. São Paulo: Hucitec: Edições Mandacaru, 2006.

CHAVES, Marcos Machado. A trilha sonora teatral em pauta: experiências de criadores de trilhas sonoras em Porto Alegre. 2011. Dissertação (Mestrado em Artes Cênicas) - Instituto de Artes - Universidade Federal do Rio Grande do Sul, Porto Alegre, 2011. Disponível em:

https://www.lume.ufrgs.br/bitstream/handle/10183/31780/000784812.pdf;sequenc e=1Acesso em: 04 jun. 2021.

DUBATTI, Jorge. Experiencia teatral, experiencia tecnovivial: ni identidad, ni campeonato, ni superación evolucionista, ni destrucción, ni vínculos simétricos. Rebento, São Paulo, v. 1, n. 12, p. 8-32, 2020. Disponível em: http://www.periodicos.ia.unesp.br/index.php/rebento/article/view/503/299.

Acesso em: 08 mar. 2021.

DUBATTI, Jorge. Filosofía del teatro III: el teatro de los muertos. Buenos Aires: Atuel, 2014.

FISCHER, Stela Regina. Processo colaborativo e experiências de companhias teatrais brasileiras. São Paulo: Hucitec, 2010.

GERBASE, Carlos. Direção de atores: como dirigir atores no cinema e TV. - 2. ed. Porto Alegre: Artes e Ofícios, 2007.

GONÇALVES JUNIOR, Antônio Luiz. O dramaturgista no processo colaborativo de criação cênica: pensamento crítico em gesto. 2019. Tese (Doutorado em Artes Cênicas) - Departamento de Artes Cênicas - Escola de Comunicação e Artes Universidade de São Paulo, São Paulo, 2019. Disponível em: https://teses.usp.br/teses/disponiveis/27/27156/tde-22072019-174906/pt-br.php. Acesso em: 08 jun. 2021.

HONAN, Park. Shakespeare: uma vida. Tradução de Sonia Moreira. São Paulo: Companhia das Letras, 2001.

JOSÉ, Carmen Lucia. Paisagem sonora: o som nas ondas do rádio. Revista de Comunicação, Cultura e Teoria da Mídia, São Paulo, n. 02, p. 176-195, 2007. Disponível em: <http://www.cisc.org.br/portal/jdownloads/Ghrebh/Ghrebh\%209/14_lucia_jose.pdf>. Acesso em 04 jun. 2021.

SÓfOCLES. Édipo Rei. Tradução de Paulo Neves. Porto Alegre: L\&PM, 2002.

STANISLAVSKI, Constantin. A Construção da Personagem. Tradução de Pontes de Paula Lima - 5. ed. - Rio de Janeiro: Civilização Brasileira, 1989.

STANISLAVSKI, Constantin. A Criação do Papel. Tradução de Pontes de Paula Lima - 2. ed. - Rio de Janeiro: Civilização Brasileira, 1984. 
Amantes em confinamento: A videochamada como dispositivo cênico

STANISLAVSKI, Constantin. A preparação do ator. Tradução de Pontes de Paula Lima - 7. ed. - Rio de Janeiro: Civilização Brasileira, 1986.

Recebido em: 15/06/2021

Aprovado em: 19/08/2021 